\title{
Study on Platelet Count on the Basis of Red Cell: Platelet Ratio
}

\author{
Authors

\section{Dr Ajamal Singh Bhayal ${ }^{1}$, Dr Mahendra Kumar Gupta ${ }^{2}$, Dr Narendra Kumar Sharma ${ }^{3}$ Dr Asim Singh ${ }^{4}$, Mr Manoj Kumar Yadav ${ }^{5}$} \\ ${ }^{1,2}$ MBBS, MD, Associate Professor, Department of Pathology \\ ${ }^{3}$ MBBS, MD, Professor, Department of Community Medicine \\ ${ }^{4}$ MBBS, MD, Assistant Professor, Department of Microbiology \\ ${ }^{5} \mathrm{MSc}$. Medical Biochemistry, Tutor, Department of Biochemistry \\ 1,2,3,4,5 Heritage Institute of Medical Sciences, Varanasi, India
}

\begin{abstract}
S
The modern hematology analyzers are able to produce platelet counts with great precision and accuracy. Our aim to verification of the reliability of the estimation technique of platelet count on the basis of red cell: platelet ratio. An overnight fast venous blood samples was collected for the following parameters: Manual Method \& Automated Method. The results of platelet count using the manual method were as follows: the range was between 100-499 $\times 10^{3} / \mu \mathrm{l}$, the mean platelet count was $301.46 \pm 44.49 \times 10^{3} / \mu \mathrm{l}$ and by using the automated method, platelet count ranged between 95-484 $\times 10^{3} / \mu l$, the mean was $328.47 \pm 54.00 \times 10^{3} / \mu l$. Red blood cell: platelet ratio method requires only an accurate RBC count performed on a calibrated hematology analyzer to calculate platelet count. This method is precise, simple and consumes less time than using a counting chamber and therefore, potentially should supersede ordinary manual counting.

KEY WORD: Red cell: platelet ratio, Manual Method \& Automated Method
\end{abstract}

\section{INTRODUCTION}

The estimation of platelet count from blood smears must be systematic each time the automated count is erroneous because even the most expensive and most effective machine is not able to replace human judgment. With the development of sophisticated automated bloodcell analyzers, the proportion of blood count samples that require a blood smear has steadily diminished and in many clinical settings is now 10 to 15 percent or less. Nevertheless, the blood smear remains crucial diagnostic aid ${ }^{1}$. Modern hematology analyzers are able to produce platelet counts with great precision and accuracy. However, in certain cases these analyzers produce erroneous platelet results, for example pseudothrombocytopenia $^{2}$, or pseudo thrombocytosis or at least obvious overestimation of the real number of platelets as in patients with acute leukemia. Because of their shape and size, hematology analyzers add several undefined particles to the platelet cluster. In some cases, this may even lead to the masking of a (possible life threatening) thrombocytopenia, and consequently the withholding of proper medication or other crucial supportive measures ${ }^{3}$. The International 
Council for Standardization in Hematology (ICSH) and the International Society of Laboratory Hematology (ISLH) recommend the counting of specifically labeled platelets relative to the RBCs with a fluorescence flow cytometer, together with an accurate RBC count determined with a semi-automated, single-channel apertureimpedance counter as a reference method for the enumeration of platelets ${ }^{4}$.

\section{MATERIAL AND METHODS}

The present study was conducted in the Department of Pathology, Heritage Institute of Medical Science, Varanasi, India. Randomly selected 65 patients attending OPD in the Heritage Institute of Medical Science during the period from July 2015 to September 2015 were included in the study. An overnight fast venous blood samples were collected and studied the following:

- Automated Method

- Manual Method

The red cell: platelet ratio was calculated in the monolayer zone of the smear as follows: The number of erythrocytes observed in a quarter of the oil-immersion field was multiplied by four instead of counting all the erythrocytes in the field. Then all the platelets in the same field were counted.

Other fields were examined in the same way until a minimum number of 1000 erythrocytes was reached. The number of platelets per 1000 erythrocytes was multiplied by the automated Red Blood Count (RBC) (x106cells/ $\mu \mathrm{l})$ to give an approximate manual count $(\mathrm{x} 103 \mathrm{cells} / \mu \mathrm{l})^{5}$.

\section{Statistical Method}

The mean, median and range of platelet count using the two laboratory methods were calculated. Simple linear regression plot was used to compare the manual with the automated platelet counts.

Intra-class Correlation Coefficient (ICC) was calculated in order to identify the degree of correspondence and the agreement between the two methods. The ICC value is measured on a scale of 0 to 1 , good reliability was assumed as an ICC $>0.75$. A paired t-test was performed, a statistically significant difference in platelet level was set at a level of $\mathrm{P}<0.05$.

\section{RESULTS}

The present study shows the results of platelet count using the manual method were as follows: the range was between $100-499 \times 10^{3} / \mu 1$, the mean platelet count was $301.46 \pm 44.49 \times 10^{3} / \mu 1$ and by using the automated method, platelet count ranged between $95-484 \times 10^{3} / \mu 1$, the mean was $328.47 \pm 54.00 \times 10^{3} / \mu 1$ (Table 1 ). The report of evaluation with the two laboratory methods gave the following equation by comparing the automated $(\mathrm{Y})$ to the manual method $(\mathrm{X})$ : $\mathrm{Y}=$ $0.9893 x-1.8621$ ( $r=0.966)$.

Table 1 shows the comparison of platelet count in manual and automated methods:

\begin{tabular}{|l|c|c|c|}
\hline & $\begin{array}{c}\text { Manual Platelet Count } \\
\left(10^{3} / \mu 1\right)\end{array}$ & $\begin{array}{c}\text { Automated Platelet Count } \\
\left(10^{3} / \mu 1\right)\end{array}$ & \multirow{2}{*}{ P- value } \\
\hline Range & $100-499$ & $95-484$ & $<0.0001$ \\
\hline Mean \pm S.D. & $301.46 \pm 44.49$ & $328.47 \pm 54.00$ & \\
\hline
\end{tabular}

Statistically significant $(\mathrm{p}$ value $<0.05)$

The paired t-test showed no significant difference between the two methods $(\mathrm{P}<0.05)$. The ICC was equal to 0.988 . The differences between the automated and manual values and their means showed that the difference mean \& standard deviation was $2.116 \pm 40.215$. It was noticed that $93 \%$ of the differences were within the agreement limits (Mean $\pm 2 \mathrm{Sd}$ ).

\section{DISCUSSION}

Even in the age of molecular analysis, the blood smear remains an important diagnostic tool. Physicians should request a blood smear when there are clinical indications for it. If error is to be avoided, sophisticated modern investigations of hematologic disorders should be interpreted in the light of peripheral blood features as well as the 
clinical context. In comparison with the procedure for an automated count, the examination of a blood smear is a labor-intensive and therefore relatively expensive investigation. A request for a blood smear is usually the result of an abnormality in the complete blood count or a response to "flags" produced by an automated instrument ${ }^{1}$. Obtaining an accurate platelet count by using an automated hematology analyzer may be complicated by the presence of particles of similar size and/ or light scatter properties (red cell fragments, microcytic red cells, apoptotic white blood cell fragments) and by giant platelets and platelet clumps ${ }^{6,7}$. Falsely low platelet counts may be the result of small clots, platelet clumping, platelet satellitism, or abnormally large platelets. Underlying causes that may be revealed by the blood smear include the May-Hegglin anomaly, microangiopathicthrombopathies and leukemias and lymphomas. High platelet counts should be confirmed microscopically with a blood smear, falsely high counts may be the result of other particles (red-cell fragments, fragments of leukemic cells, or fungi) being counted as platelets $^{8,9,10}$. Examination of the blood smear is also important in patients with thrombocytosis to look for evidence of a myeloproliferative disorder, such as giant platelets, or an increase in the basophil count; the latter is not reliably detected by automated counters. A sudden, unexpected improvement in the platelet count also should be confirmed by blood smear examination, since such an improvement may be factitious ${ }^{9}$. Until recently, the only reference method for platelet counting was the manual phase contrast microscope chamber counts ${ }^{11}$ in which platelets are counted manually with a haemocytometer, such as Neubauer chamber. This is laborious, timeconsuming and above all, an imprecise technique. The interoperater coefficient variant of this method can be up to $25 \%$. However, it is still most widely used reference method ${ }^{12}$. Even if the manual platelet numeration, using a counting chamber, remains the technique of reference, it consumes more time and to be more precise, requires a phase-contrast microscope, which is not always available in routine laboratories ${ }^{13}$. That is why the proposed method is better, since it is faster, taking only five minutes on average per patient, while demonstrating good precision. Some authors recommend calculating the average number of platelets counted in 10 immersion fields; the adequate values are included between 8 to 20 platelets per field ${ }^{14,15}$. The average number of platelets is then multiplied by a factor of 20,000 for wedge preparations or 15,000 for monolayer preparations in order to obtain and estimate the platelet count, but this method is approximative and does not give the real number of platelets. Comparing automated and manual, using red cell: platelet ratio method, platelets counting techniques showed that there was no significant difference $(\mathrm{P}<0.05)$ between the mean and range of platelet counts using these two methods.

The ICC was calculated in order to identify the reliability of the manual technique in comparison to the automated method ${ }^{16}$. The ICC value is measured on a scale of 0 to 1 , and good reliability was generally assumed as an ICC $>0.75^{17}$. In this study, the ICC was equal to 0.988 , which is widely greater than this limit. In addition, $93 \%$ of the differences between automated and manual counting methods were within the agreement limits (Mean $\pm 2 S d$ ).

\section{CONCLUSION}

These findings suggest that the red blood cell: platelet ratio method requires only an accurate RBC count performed on a calibrated hematology analyzer to calculate platelet count. This method is precise, simple and consumes less time than using a counting chamber and therefore, potentially should supersede ordinary manual counting.

\section{BIBLIOGRAPHY}

1. Bain BJ. Diagnosis from the blood smear. N Engl J Med 2005;353:498-570.

2. Gowland E, Kay Hem, Splillman JC, et al. Blood cell morphology in health and disease. In: Lewis SM, Bain BJ, Bates I, 
editors. Dacie and Philadelphia: Churchill Livingstone, 2006:79-113.

3. Meer W V, Mackenzie M A, Dinnissen J W and de Keijzer M H. Pseudoplatelets: a retrospective study of their incidence and interference with platelet counting J. Clin. Pathol. 2003;56:772-774.

4. International Council for Standardization in Haematology expert Panel on Cytometry. Platelet Counting by the RBC/Platelet Ratio Method. A "Reference Method. American journal of Clinical Pathology 2001;115;460-464.

5. Bain BJ, Lewis SM, Bates I. Basic haematological techniques. In: Lewis SM, Bain BJ, Bates I, editors. Dacie and Lewis: Practical Haematology. $10^{\text {th }}$ ed. Philadelphia: Churchill Livingstone, 2006:26-54.

6. Charie LA, Harrison P, Smith CU, Cobb JR, Briggs C, Machin S. Accuracy in the low platelet count range: a comparison of automated platelet counts on Beckman Coulter high-volume hematology analyzers with the ISLH/ICSH platelet reference method. Lab Hematol 2001;7:236-44.

7. Rowan RM. Platelet counting and the assessment of platelet function. In:Koepke JA, editor. Practical Laboratory Hematology. New York, NY: Churchill Licvingston, 1999:57-70.

8. Latif S, CVeillon DM, Brown D, et al. Spurious automated platelet count: enumeration of yeast forms as platelets by the Cell-DYN 4000. Am J ClinPathol 2003; 120:882-885.

9. Arnold JA, Jowri Z, Bain BJ. Candida glabrata in a blood smear. Br J Haematol 2001;104: 13-16.

10. Kakkar N. spurious rise in the automated platelet count because of bacteria. J ClinPathol 2004;57: 1096-1097.
11. K. H. Hong, M. J. Kim, K. W. Lee. Platelet count evaluation using three automated haematologyanalysers compared with the immunoplatelet reference method and estimation of possible inadequate platelet transfusion. Int. J. Lab. Hem. 2009,31, 298-306.

12. Harrison P., Horton A., Grant D., Briggs C. \&MacHin S. Immunoplatelet counting: a proposed new reference procedure. British Journal Haematology 2000, 108.228-235.

13. Brown BA. Hematology: Principles and Procedures. $6^{\text {th }}$ ed. Philadelphia: Lea and Febiger, 2000.

14. Mohapatra S, Pradhan BB, Satpathy UK, Mohanty A, Pattnaik JR. plateletstimatioin: its prognostic value in pregnancy induced hypertension. Indian J PhysiolPharmacol 2007;51:160-164.

15. Shrout PE, Fleiss JL. Intraclass correlations: uses in assessing rate reliability. Psychol Bull 1979'86:420-428. (Cited)

16. Portney LG, Watkins MP. Foundations of clinical research. Applications to practice. Norwalk, CT, USA: Appleton and Lange, 2002:509-514.

17. Bland JM, Altman DG. Statistical methods for assessing agreement between two methods of clinical measurement. Lancet 1986;1;307-310. (Cited)

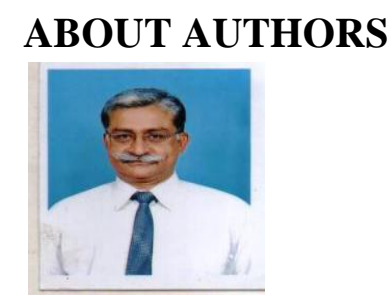

Dr Ajamal Singh Bhayal, MBBS,MD Associate Professor, Department of Pathology, Heritage Institute of Medical Sciences, Varanasi, India Email:asbhayal@gmail.com 